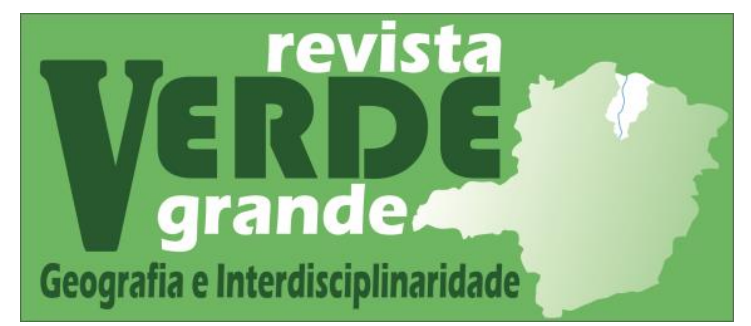

Volume 2, n‥ 1 (2020)

ISSN: 2675-2395

https://doi.org/10.46551/rvg2675239520201324

\title{
AÇÕES COMPARTILHADAS PARA USO E CONSERVAÇÃO DOS RESERVATÓRIOS BILLINGS E BARRA BONITA
}

\author{
Shared actions for use and conservation of Billings and Barra Bonita reservoirs
}

Daniel Ladeira Almeida ${ }^{1}$ https://orcid.org/0000-0001-5843-1223

\footnotetext{
1 Doutor em Energia - UFABC. Professor de Geografia - Secretaria de Estado da Educação de São Paulo. E-mail: $\underline{\text { ufabcdaniel@gmail.com }}$
}

\section{Resumo}

Os reservatórios de água, além de garantir a potencialidade das usinas hidrelétricas, contribuem para o abastecimento público de muitas cidades localizadas próximas a seus domínios hídricos. Na perspectiva de uma pesquisa qualitativa, este artigo tem como objetivo analisar criticamente a gestão compartilhada do reservatório Billings e do reservatório de Barra Bonita, ambos localizados no Estado de São Paulo, buscando compreender os conflitos que envolvem o uso dos reservatórios e analisar os fatores que resultam nos principais passivos ambientais envolvidos. A hipótese geral sustenta a ideia de que uma gestão compartilhada pode subsidiar a redução dos passivos ambientais existentes nos reservatórios. Trata-se de uma pesquisa realizada por meio da análise de ações desempenhadas por empresas controladas pelo poder público e privado. As análises dos resultados foram norteadas por referenciais teóricos e experimentais. Como metodologia, foram aplicadas entrevistas a representantes da EMAE, CETESB, SABESP e AES-Tietê visando compreender a gestão dos reservatórios e permitir os fatores que resultam nos principais passivos ambientais envolvidos. Os resultados identificaram dificuldades em conduzir uma gestão compartilhada entre os usuários e operadores dos reservatórios, e a partir de tal análise, será possível elaborar medidas que reduzam os passivos ambientais que atingem os reservatórios.

Palavras-chave: Hidrelétricas, gestão compartilhada, múltiplos usos da água.

\begin{abstract}
The water reservoirs, in addition to guaranteeing the potential of hydroelectric plants, contribute to the public supply of many cities located close to their water domains. In the perspective of a qualitative research, this article aims to critically analyze the shared management of the Billings reservoir and the Barra Bonita reservoir, both located in the State of São Paulo, seeking to understand the conflicts that involve the use of the reservoirs and to analyze the factors that result in the main environmental liabilities involved. The general hypothesis supports the idea that shared management can subsidize the reduction of environmental liabilities in the reservoirs. This is a research carried out through the analysis of actions performed by companies controlled by public and private authorities. The analysis of the results was guided by theoretical and experimental references. As a methodology, interviews were applied to representatives of EMAE, CETESB, SABESP and AES-Tietê aiming to understand
\end{abstract}


the management of the reservoirs and allow the factors that result in the main environmental liabilities involved. The results identified difficulties in conducting a shared management between users and operators of the reservoirs, and from such analysis, it will be possible to develop measures that reduce the environmental liabilities that affect the reservoirs.

Keywords: hydroelectric plants, shared management, multiple uses of water.

\section{Introdução}

A ocupação desordenada dos grandes centros urbanos, quando o grande contingente de pessoas lança diretamente efluentes domésticos não tratados nos corpos d'água e ocupa irregularmente áreas destinadas a proteção dos recursos hídricos, potencializa o conflito socioambiental (JACOBI et al., 2015b).

As questões relacionadas à baixa qualidade da água em consequência do lançamento de efluentes domésticos e industriais sem o devido tratamento começam a limitar oferta de água em regiões de alta concentração demográfica (JACOBI et al., 2015b). Nos maiores centros urbanos paulistas, por exemplo, os reservatórios com as fontes de captação de água para o abastecimento público estão sujeitos a poluição por falta de ligação a rede coleta de esgoto para ser efetivamente tratado, afetando a qualidade e a disponibilidade de água (CARMO, 2001).

Segundo o Instituto Trata Brasil (2015), existe uma significativa ociosidade nas redes de esgotamento sanitário em todo território nacional. Mesmo que tenha a existência da rede, os usuários não estão conectados, mesmo havendo dispositivo legal que obriga à interligação, como o art. 45 da Lei Nacional de Saneamento Básico.

Esses fatores são desafios que exigem ações efetivas dos gestores que operam e se utilizam dos reservatórios. Tais agentes podem estar envolvidos em um modelo de gestão pública, em que há intervenção do Estado na atividade produtiva (ABRANCHES, 1979) ou em um modelo de gestão privada, que visa à racionalização das atividades, afinando-se a organização, regulação e planejamento territorial com os desígnios de grupos corporativos nacionais ou multinacionais (RAMALHO, 2006).

Diante da contextualização apresentada, esse artigo analisa a gestão de reservatórios e os conflitos pelo uso da água por meio de entrevistas realizadas com representantes de empresas públicas e privadas que operam e utilizam reservatórios construídos para a finalidade hidrenergética e que foram vocacionados para o abastecimento público. Essas empresas e órgãos têm como principal fonte de recursos a operação das águas dos reservatórios Billings e Barra Bonita. A escolha da empresa privada AES-Tietê (Barra Bonita) e da empresa pública Empresa Metropolitana de Águas e Energia S.A. (Emae/Billings) permite fazer uma análise crítica da gestão compartilhada com as instituições que fiscalizam, monitoram e utilizam os reservatórios.

As empresas participaram da pesquisa por meio de entrevistas realizadas no terceiro trimestre de 2015 com representantes com mais de cinco anos de atuação nas empresas, sendo três públicas, uma operadora (Emae) e uma usuária (Sabesp) das águas do reservatório Billings e outra encarregada de 
fiscalizar e monitorar a poluição (Cetesb); além de uma empresa privada (AES-Tietê) que opera as águas de Barra Bonita. As entrevistas, amparadas pela fundamentação teórica, buscam identificar as ações compartilhadas entre os usuários e operadores dos reservatórios pelo uso da água, e, a partir de um processo de análise, propõem-se elaborar medidas que reduzam os conflitos pelo uso da água e contribuam na gestão dos recursos hídricos de forma a ampliar a produtividade de energia elétrica, mantendo ativos os usos múltiplos dos reservatórios Billings e Barra Bonita.

As explanações obtidas nas entrevistas almejam estabelecer conexões lógicas e complexas entre as tendências existentes no plano institucional, operacional, econômico e socioambiental das empresas que atuam nos respectivos reservatórios.

O método utilizado a fim de comentar as respostas dos entrevistados(as) foi embasado em uma análise bibliográfica sobre o tema. A indução e o empirismo também orientaram o prognóstico, pois a pressão de impactos ambientais a que estão sujeitos os reservatórios Billings e Barra Bonita.

O questionário foi aplicado presencialmente aos representantes da Emae, da Cetesb, da Sabesp e da AES-Tietê, acompanhado do Termo de Consentimento Livre e Esclarecido (TCLE) ressaltando que a cooperação deve ser voluntária e sigilosa, de forma que os dados obtidos serão utilizados exclusivamente para fins da pesquisa.

\section{Como gerir um reservatório de forma compartilhada?}

A construção de reservatórios hidrelétricos induz a ocupação demográfica e estimula o desenvolvimento produtivo regional em função da oferta de água e energia elétrica. Em grandes cidades, como São Paulo, consolidadas a montante de rios estão sujeitas a maior escassez hídrica, por haver menor quantidade de afluentes; dessa forma os reservatórios se tornam importantes reservas hídricas. A flexibilização das leis ambientais e ausência de fiscalização efetiva na ocupação em áreas de mananciais compromete o aporte hídrico e qualidade da água, motivados por movimentos de periferização e déficit habitacional.

A partir de 2014 os períodos de estiagem e níveis pluviométricos têm sido anormais para os padrões climatológicos regionais, mesmo assim, a escassez hídrica é o reflexo da ausência de planejamento estratégico e do crescimento populacional que afeta a Região Sudeste nos últimos dez anos (CÔRTES; TORRENTE, 2015).

Há estimativa que em 2017 que a população no Estado de São Paulo seja de 43.674.533 (SEADE, 2016), entretanto as instituições que operam e utilizam os recursos hídricos dificilmente definem investimentos na ampliação do aporte hídrico ao mesmo ritmo que a demanda populacional e em consonância com os indicadores ambientais projetados nas alterações climáticas. 
Tais condições de escassez hídrica poderiam ser revertidas com um planejamento estratégico adequado e embasado nas informações climáticas (CÔRTES; TORRENTE, 2015). As causas da escassez hídrica não podem ser reduzidas apenas às menores taxas pluviométricas ocorridas nos últimos anos, mas a fatores relacionados à ineficiência da gestão dos recursos hídricos voltada para garantia da oferta de água (ANA, 2016).

Em regiões com alta concentração populacional a demanda por água é crescente, assim como, a carga de poluição em razão dos efluentes domésticos e industriais lançados sem tratamento adequado nos cursos hídricos (JACOBI; CIBIM; LEÃO, 2015).

As medidas para inibir a emissão de efluentes nos recursos hídricos e a escassez hídrica devem ser gradativas e permanentes. No Brasil tais medidas foram tardias após vastas discussões foi regulamentado o Plano Nacional de Recursos Hídricos a partir da Lei no 9.433, de 8 de janeiro de 1997; antes disso investimentos com saneamento eram inferiores comparados aos setores de energia:

O PNRH vem ao encontro dessa ação estratégica e as bases conceituais para a sua construção estão alicerçadas nos fundamentos, nos objetivos e nas diretrizes gerais de ação, previstos na Lei Federal n ${ }^{\circ}$ 9.433/1997, destacandose: a ratificação da dominialidade pública das águas; a prioridade para o consumo humano e para a dessedentação de animais em situações de escassez; os usos múltiplos das águas; seu valor econômico; a bacia hidrográfica como unidade territorial para implementação da política; a descentralização e a participação social no processo de gestão; a utilização integrada e sustentável da água; os conceitos de integração e articulação, tanto do ponto de vista dos processos socioambientais quanto políticos e institucionais (BRASIL, 2006, p. 16).

Mesmo com a existência de uma Lei que regulamenta um sistema de gestão integrado, participativo e descentralizado, as ações desempenhadas pelo governo do Estado de São Paulo, representado pela Sabesp e pelos gestores da água da bacia hidrográfica do Rio Tietê, não têm sido capazes de evitar a grave ameaça de falta de água no estado (JACOBI; CIBIM; LEÃO, 2015).

Os marcos regulatórios são fundamentais para definir investimentos no setor e definir ações de conservação e recuperação dos recursos hídricos. Isso consiste em gerir os recursos hídricos, de forma integrada, com vista a manutenção da produção de água e a garantia da qualidade da água. Entretanto, o uso compartilhado da água para abastecimento e geração de energia elétrica é passível de conflitos, pois a geração de energia independe de níveis superiores de qualidade, assim como exigem o aproveitamento hídrico para o abastecimento público. Nesse sentido, foi feita a respectiva indagação referente a preocupação da empresa 
com uma gestão participativa que visa reduzir os conflitos pelo uso da água. Esse questionamento foi feito por meio da pergunta 5 aos entrevistados da Emae:

A geração hidrenergética e o abastecimento público tem se tornado um dos grandes desafios para administrações e comunidades atuais. Visando os usos múltiplos da água a empresa promove uma gestão participativa para a redução dos conflitos? Justifique.

Para RE1, almejar uma gestão participativa é meta da empresa, porém as perspectivas que a concretizam estão mais reduzidas; por enxergar possibilidades muito distantes de uma política pública capaz de arregimentar os esforços:

O que percebo é infelizmente uma visão imediatista e políticas desconexas, em especial entre os diferentes municípios que compõe a bacia da Billings. Interesses conflitantes, necessidade de expansão urbana sobre as áreas de mananciais e setores econômicos e políticos determinando o uso do solo. Acho que o exemplo mais bem-sucedido nesse campo é o exemplo da cidade de Extrema, no sul de Minas, que remunera o produtor de água, incentiva o plantio e recomposição de florestas e consegue visualizar o proprietário como um parceiro e não como um empecilho ao desenvolvimento econômico (RE1).

A experiência exemplificada pela(o) entrevistado(a) reúnem medidas como recomposição de mata ciliar e de vegetação de topos de morros, em áreas de nascentes, podem fazer para o aumento da vazão dos rios de determinada região. Essas medidas compõem um serviço ambiental que institui a cobrança pelo uso da água ao incentivo para o conservador de água, concedendo apoio ao proprietário rural que aplique ações de preservação e conservação dos mananciais, entendendo que as boas práticas adotadas para melhorar a oferta e a qualidade de água devem ser remuneradas como fator de estímulo e renda (TEIXEIRA, 2011). Para o(a) entrevistado(a), o comprometimento financeiro do usuário de recursos ambientais pode contribuir para manutenção dos recursos e reduzir a propensão de ameaças ao meio ambiente.

Os riscos aos recursos ambientais se intensificam, mas dificilmente convertem politicamente num conjunto de medidas preventivas para a superação das causas que convergem nos riscos, e [...] não se sabe ao certo qual o tipo de política e de instituições políticas que estariam em condições de adotá-las. O que surge, na verdade, é uma solidariedade ininteligível, correspondente à ininteligibilidade dos riscos (BECK, 2011, p. $58)$.

Para Jacobi et al.: 
O maior desafio é viabilizar uma política abrangente, envolvendo a sociedade civil em processos de consulta e decisórios na gestão da água. Esta orientação corresponde com uma tendência internacional estimulada pelos graves problemas na qualidade e quantidade da água disponível no planeta, ocasionados pela forma pela qual foram geridos os recursos hídricos (JACOBI et al., 2015, p. 18).

A ampliação dos passivos ambientais que atingem os reservatórios acentua os conflitos e exigem uma gestão participativa que envolva a sociedade civil nas ações o uso e conservação dos recursos hídricos. Para isso é necessário que todos os atores envolvidos tenham a dimensão dos riscos, e é importante que informações claras e objetivas atinjam os mais distintos segmentos da sociedade, ao considerar a água um recurso natural de uso comum:

A "irracionalidade" da "percepção" pública do risco que seja "desviante" consistirá no fato de que, aos olhos dos técnicos, a maioria da população ainda se comporta como estudantes do primeiro semestre de engenharia, ou ainda pior. São de fato ignorantes, mas mostram boa vontade, esforçam-se, sem, contudo, ter a mínima ideia. Nessa imagem, a população é formada por um bando de aspirantes de engenheiros isolados, que ainda não dispõem dos conhecimentos necessários. Basta empurrá-la com detalhes técnicos para que ela então se associe ao ponto de vista e à avaliação dos especialistas sobre o manejo técnico e, portanto, sobre como os riscos não representam qualquer risco (BECK, 2011, p. 69).

Para RE2, a atribuição para a gestão participativa deve ser coordenada pelo primeiro setor (Estado). Apesar disso, a empresa (Emae) já promoveu no passado trabalhos de inserção socioambiental, na busca de capacitar as comunidades locais para se apoderar medidas de conservação ambiental, porém não foram adiante devidos principalmente à falta de recursos.

A conscientização e reconhecimento social dos riscos coincidem com a história da desmistificação das ciências. O passado deixa de ter força em relação ao presente, e o futuro ainda inexistente é construído como causa da vivência do presente (BECK, 2011).

Nesse sentido, ações de capacitação das comunidades locais à luz das experiências socioambientais cotidianas podem impedir a ocorrência de futuros riscos ambientais. Os riscos são mais suscetíveis aos grupos de menor renda da população, são oneradas no longo prazo por conta de diversos poluentes no ar, na água e no solo. E com a proeminente redução da renda, uma maior tolerância pode ser gerada (BECK, 2011).

A irradiação da ocupação em áreas de drenagem dos reservatórios é forçada pela comercialização de loteamentos clandestinos com terrenos de baixo valor imobiliário. 
Dessa forma se sequenciam os passivos ambientais quais estão sujeitos os reservatórios, com destaque para a remoção da mata ciliar, assoreamento, lançamento de efluentes não tratados e impermeabilização dos solos.

O adensamento urbano aliado à ineficiência na execução das legislações ambientais contribuiu para a ocupação das áreas de mananciais do reservatório Billings, isso abriu precedentes para que ocorressem impactos socioambientais que comprometem a quantidade e qualidade da água.

O Quadro 1 reúnem os fatores que destacam os atores envolvidos nos impactos socioambientais suscetíveis de conflitos.

Quadro 1 - Impactos socioambientais suscetíveis de conflitos

\begin{tabular}{|l|l|l|}
\hline \multicolumn{1}{|c|}{ Atores } & \multicolumn{1}{c|}{ Impactos socioambientais } & \multicolumn{1}{c|}{ Conflitos } \\
\hline $\begin{array}{l}\text { Prefeituras e empresa que } \\
\text { opera reservatório }\end{array}$ & $\begin{array}{l}\text { Ocupação desordenada e falta } \\
\text { de tratamento de efluentes em } \\
\text { áreas mananciais do } \\
\text { reservatório }\end{array}$ & $\begin{array}{l}\text { Investimentos insuficientes } \\
\text { em habitação e de } \\
\text { fiscalização }\end{array}$ \\
\hline $\begin{array}{l}\text { Empresa que opera } \\
\text { reservatório e o Ministério } \\
\text { Público }\end{array}$ & $\begin{array}{l}\text { Lançamento contínuo de águas } \\
\text { do rio Pinheiros no reservatório } \\
\text { Billings }\end{array}$ & $\begin{array}{l}\text { Impedimento do Ministério } \\
\text { Público ao projeto de } \\
\text { flotação }\end{array}$ \\
\hline $\begin{array}{l}\text { Grandes empreendimentos e } \\
\text { concessionária de rodovias }\end{array}$ & $\begin{array}{l}\text { Assoreamento e } \\
\text { desflorestamento em áreas de } \\
\text { mananciais }\end{array}$ & $\begin{array}{l}\text { Morosidade na } \\
\text { compensação ambiental } \\
\text { após a conclusão da obra }\end{array}$ \\
\hline
\end{tabular}

Fonte: Elaboração do autor

De acordo com Aquino (2012), entretanto, é fundamental promover iniciativas que estimulem o reflorestamento das margens dos reservatórios, como ocorre no reservatório de Itaipu. Nesse caso o consórcio binacional idealizou o Projeto Cultivando Água Boa, que possui aproximadamente 20 subprogramas que têm como objetivos principais a implantação de corredores ecológicos e reflorestamento de margens para recuperação de microbacias, envolvendo a participação de 29 municípios, órgãos governamentais, ONGs, instituições de ensino, cooperativas, associações comunitárias e empresas:

Assim, nada impede a priori que operadores privados possam atuar de forma articulada com as prefeituras e entidades comunitárias em intervenções urbanas integradas, visando atender populações desfavorecidas em áreas de sub-habitação; a necessidade de regulação e as assimetrias de informação e poder entre reguladores e regulados não são menos importantes em relação aos operadores públicos, da mesma forma que as dificuldades de integração entre infraestruturas e serviços de saneamento ambiental; enfim, a gestão pública não é menos sujeita a corrupção, e nem toda concessão ao setor privado implica necessariamente aumentos extraordinários de tarifas ou o fim de subsídios cruzados (VARGAS, 2005, p. 80). 
$\mathrm{Na}$ perspectiva da realidade presente no reservatório de Barra Bonita, inserido na bacia do rio Tietê, ao representante da operadora privada AES-Tietê foi feita a seguinte indagação por meio da pergunta 1:

Como se posiciona os gestores de um reservatório quando ocorre a pressão sobre os recursos hídricos em detrimento do conflito entre alta demanda pelos abastecimentos público, e o setor hidrenergético? Existe um modelo de atuação do setor energético na gestão do reservatório?

Nessa perspectiva desse questionamento, cabe a empresa que opera o reservatório regular a vazão do reservatório, principalmente em situações de escassez hídrica sob o risco de comprometer turbinas e geradores da usina. Porém, são envolvem decisões operacionais que impactam os múltiplos usos e motivam conflitos ao impedir a utilização do reservatório para navegação, irrigação e pesca (GALVÃO; BERMANN, 2015). Diante dessa realidade relacionada aos conflitos, RA os autores afirmam que:

A AES Tietê em atenção às recomendações dos órgãos competentes e pelas condições hidrológicas restritivas que afetem seus reservatórios preza pelo uso múltiplo deste ativo. Diariamente são realizadas simulações/estudos sobre as condições hidrológicas dos reservatórios e medidas operacionais são tomadas a partir destes estudos. Tal medida é realizada atendendo recomendações de órgãos como ANEEL - Agência Nacional de Energia Elétrica, ONS - Operador Nacional do Sistema e IBAMA, a fim de preservar os níveis da represa, evitar o esgotamento do recurso hídrico na localidade e eventual dano ao meio ambiente e todos os seus usuários múltiplos (RA).

Dentre as recomendações exigidas pela Aneel, destaca-se a avaliação do assoreamento em reservatórios. É necessário que o operador do reservatório realize com regularidade os níveis de granulometria em suspensão e do leito. Também é necessária a medida da carga de fundo em estudos sedimentológicos para pequenos e médios reservatórios, uma vez que o sedimento grosso (areia) nunca é descarregado pelos condutos e vertedouro, ficando depositado no reservatório; com exceção para pequena quantidade de areia descarregada em ocasião de enchentes (ANEEL, 2000).

Segundo Campagnoli (2012, p. 12):

A gestão de reservatórios de hidrelétricas é vital à preservação do potencial hidráulico do aproveitamento hidrelétrico. Uma vez instalado o reservatório, e com a usina em operação, o adequado gerenciamento do lago, de suas áreas marginais e da bacia contribuinte pode proporcionar uma sobrevida maior ao aproveitamento hidrelétrico para novos contratos e concessões. 
Entretanto, o(a) entrevistado(a) não cita o envolvimento de outras instituiç̧̃̃es tendo em vista uma gestão compartilhada para o uso e manutenção do reservatório. A participação de outras instituições ocorre somente para o cumprimento de determinações previstas para o estabelecimento da concessão.

A AES, no último relatório, ressalta a proporção de energia produzida de acordo com o regime de chuvas ocorridas em 2014. Os níveis dos reservatórios das regiões Sudeste encerraram 2014 com cerca de 19,4\% da sua capacidade total, inferior aos níveis verificados no final de dezembro de 2013, que foi de 43\% (AES, 2014).

Em um país extremamente dependente da geração hidrelétrica, a compreensão da crise hídrica envolve a valorização do recurso hídrico como bem público finito e a conscientização de um uso mais racional e compartilhado da água são essenciais para garantir da oferta hídrica para os usos múltiplos. Para isso, é necessário aprimorar técnicas de reuso da água, reduzir o desperdício pelos diferentes setores usuários, além de implementar ações de conservação de mananciais e de investimento em infraestrutura com foco na segurança hídrica de forma a garantir maior capacidade de reservação e de acesso à água (ANA, 2015).

Ações públicas e privadas e conflitos no uso da água dos reservatórios Billings e Barra Bonita

A ideia de conflito ambiental foi construída intrínseca à problemática da escassez quantitativa, e as estratégias associadas ao diagnóstico tendem ora a esvaziar o debate político, que é absorvido pela busca do aperfeiçoamento dos indicadores técnico-científico da crise ambiental; ora a justificar soluções autoritárias e meritocráticas em nome do bem-estar da humanidade (ACSELRAD, 2004).

Segundo Acselrad (2004), os conflitos ambientais podem ser compreendidos de duas formas: o primeiro, o conflito por distribuição de externalidades, proveniente da dificuldade dos geradores de impactos externos assumiram a responsabilidade por suas consequências; o segundo está associado ao conflito pelo uso dos recursos naturais, decorrente da dificuldade de se definir propriedade sobre os recursos: "Os conflitos, nesta perspectiva, estariam associados aos espaços sociais que escapam à ação do mercado, envolvendo recursos que não tem preço e que não são objetos de apropriação privada (ACSELRAD, 2004, p. 18)”.

Nesse sentido, ao considerar a água um recurso ambiental de uso comum impedida de ser apropriada de forma privada, foi feito o seguinte questionamento aos(as) entrevistado(as) da Sabesp, por da pergunta 1: 
Como se posiciona os gestores de um reservatório quando ocorre a pressão sobre os recursos hídricos em detrimento do conflito entre alta demanda pelo do setor de saneamento na gestão do reservatório?

Para o(a) entrevistado(a) RS, partir da sua experiência sobre assunto, afirma que o ciclo do saneamento básico (água e esgoto), denominados Saneamento Ambiental Tarifado, têm etapas amplamente sedimentadas na cultura organizacional da Sabesp e de todas as outras companhias de saneamento básico estaduais existentes no Brasil. Inclusive antes do marco regulatório do setor de saneamento (Lei Federal: 11.445/07), havia empresas estaduais que cuidavam apenas da distribuição de água e não tinham a atribuição de operar o sistema público de esgotamento sanitário, também não tinham a obrigação de universalizar com equidade saneamento rural dentro de uma cidade sob concessão:

Verifica-se que muitas concessionárias ainda não se deram conta da importância de ações integradas, voltadas à proteção florestal de seus reservatórios e à geração de renda da população circunvizinha. Os planos e programas de trabalho não recebem a prioridade necessária, de modo que a implementação de algumas ações depende mais da pressão das instituições de gestão ambiental (Federal e Estadual) do que de iniciativas espontâneas da própria concessionária (AQUINO, 2012, p. 138).

A Sabesp é uma empresa de economia mista, de capital aberto, que tem o governo do estado de São Paulo como principal acionista, o que a caracteriza como uma empresa pública; pois é controlada principalmente pelo Estado.

Mesmo assim empresas de saneamento de capital misto abdica o Estado de exercer a aplicação de recursos obtidos com impostos nas demandas evidenciadas pelo setor de saneamento, e deixando-o na condição de investidor, o qual busca viabilizar o seu lucro nas ações que detém e, também, cria agências de regulação no interior do seu aparelho gestor:

Deixa de investir diretamente em impostos e passa a esperar pelo lucro das ações que possui na empresa, que detém maioria das ações. Acontece eventualmente que esse lucro de investidor (no caso, o Estado) serve para financiar outras necessidades da sua administração e não as dos setores ligados à empresa na qual foi aberto o capital (AUTOMARE, 2015, p. 106).

Para RS, os conflitos setoriais se dão nas etapas de manipulação, operação e uso da água. E na ótica da gestão hídrica, instituições públicas como DAEE, Secretarias, ANA, ARSESP, Ministérios, têm a autoridade funcional de definir os usos das águas dos 
reservatórios e estão se aperfeiçoando para sempre garantir as determinações dos marcos legais.

A forma de regulação dos serviços de saneamento impacta positiva ou negativamente a qualidade das águas, o que exige as ações sejam integradas e contínuas. Para isso, é importante que o tratamento de efluentes garanta qualidade dos rios, permitindo sua utilização pelas populações a jusante; exercer a limpeza urbana com o propósito de que os resíduos sólidos acabem no leito dos rios; realizar obras de drenagem para minimizar os riscos de inundação, e propor que as águas pluviais, sejam tratadas antes de chegarem aos rios, para evitar a poluição difusa (GRANZIERA, 2014).

Para que essas medidas sejam implantadas é fundamental, uma articulação permanente entre Municípios, Estados, União e demais responsáveis pela gestão das águas. Isso consiste em superar a falácia de que manter rios limpos é difícil, caro e por isso não vale o esforço. Valorizar as ações que promovam o saneamento básico proporciona redução dos custos com relação à saúde pública (GRANZIERA, 2014).

Segundo RS, no setor de saneamento é preciso analisar dois instantes, entre os anos de 2003 e 2013. Em 2003 houve um ciclo hidrológico seco em toda a região metropolitana de São Paulo, podendo ser questionada a magnitude, mas em 2013 houve um ciclo de estiagem que foi administrado por uma visão operacional (técnica). Não existiu o envolvimento de agências reguladoras, e a Sabesp se concentrou na gestão dos níveis do reservatório do Cantareira até o último minuto sem o envolvido de outras instituições e pressionada pela demanda por água (entrincheirada), mas houve uma sequência de chuvas de verão, que recuperou os níveis dos seis lagos do reservatório do Cantareira 50\% do abastecimento da conurbação urbana.

Além das questões pluviométricas, outros fatores contribuíram para a diminuição da disponibilidade de água, como a ampliação do abastecimento público devido ao aumento populacional, consequentemente aumento da ocupação do solo proporcionando mudanças nos níveis de infiltração e escoamento da água e aumento de atividades produtivas poluidoras e assentamentos irregulares, contribuindo o lançamento de efluentes não tratados (GALVÃO; BERMANN, 2015).

Para RS, o excesso de reservação de água em 2011, no sistema Cantareira, e com distanciamento nas discussões institucionalizas entre Ministério Público estadual, ARSESP e a Sabesp. Isso fez com que a Sabesp não estruturasse efetivamente um plano de ampliação da oferta de água bruta (insumos), se tornando, em anos posteriores, um estopim para crise hídrica que atingiu o sistema Cantareira. 
Em 2014, as bacias de contribuição do Sistema Cantareira contaram com precipitações próximas as mais baixas já registradas, o que impediu a recuperação dos níveis dos reservatórios. Entre o mês de outubro de 2013 até março de 2014, foi registrada uma redução no volume de precipitação nas bacias dos rios Piracicaba, Capivari e Jundiaí, mananciais que abastecem o Sistema Cantareira; isso ocasionou redução das vazões médias mensais aos reservatórios do Sistema Cantareira, com uma vazão média anual igual a 8,70 $\mathrm{m}^{3} / \mathrm{s}$, que é o menor valor no histórico desde 1930 , o que corresponde a cerca de $22 \%$ da média anual do histórico $\left(39,44\right.$ m³/s) e a $40 \%$ da vazão média de $1953\left(21,81 \mathrm{~m}^{3} / \mathrm{s}\right)$, que era, até então, o menor valor de vazão média anual do histórico (ANA, 2015):

A diminuição do volume de precipitações e as mudanças apresentadas no padrão climático do Sudeste do país a partir de 2012 já indicavam que o abastecimento de água e atividades correlatas poderiam ficar comprometidos nos anos seguintes. Em realidade, diversos estudos sobre a disponibilidade hídrica na Região Metropolitana de São Paulo e projetos que buscavam opções para o abastecimento indicavam que tais problemas já eram previstos desde o início dos anos 2000 (GALVÃO; BERMANN, 2015, p. 57).

Em 2013, RS relata que a crise hídrica generalizada na RMSP, acompanhada da crise energética no Sudeste e Nordeste propôs uma outra forma de administração da crise com o envolvimento das instituições, adquirindo maior aprendizado na tomada de decisões. Com esta função mediadora das instituições de governo sobre os setores de saneamento, energia, agricultura, turismo, entre todos os múltiplos usos; fez com que houvesse um grande avanço de políticas públicas de Estado, que sobrepõe aos interesses corporativistas setoriais. Esses interesses têm duas intensidades um mais forte das empresas e setores predominantemente estatais e um mais fraco, com maior poder econômico, dos serviços públicos sob a concessão privada, como o energético:

A descentralização do poder de decisão - combinada com a centralização de diretrizes e a democratização dos órgãos desse sistema - pode significar um marco nas experiências de institucionalização da participação da sociedade na formulação, implantação e avaliação de políticas públicas no Brasil. Um sistema com essa complexidade, sem uma diretriz central, poderia se tornar inócuo, não apresentar resultados ou perder o seu caráter sistêmico. Sem a descentralização, as decisões e ações poderiam se perder na irracionalidade administrativa. Sem a democratização, transferindo o poder das estruturas estatais para um novo espaço público compartilhado, com novos significados, a legitimidade das decisões poderia se perder na falta de transparência (GOMES; BARBIERI, 2004, p. 19).

Para RS, há um histórico de maior dominância das decisões em favor do setor energético, pelo poder econômico. O descontrole histórico sobre usos dos agronegócios e os 
reservatórios para abastecimento de água ficam circunscritos à exclusividade e isolamento setorial no volume, não às recargas, que nos levaram em boa parte a escassez quando mais necessitamos de água em situação de crise hídrica.

$\mathrm{O}$ (a) entrevistado(a) ressalta a importância de os gestores de recursos hídricos ter uma visão abrangente sobre os usos dos recursos hídricos, e a necessidade de eleger prioridades em momentos de escassez. Isso exige discussão e planejamento que atenda às demandas futuras:

Apesar, no entanto, do cenário que se desenhava, os gestores públicos e privados do estado de São Paulo não priorizavam em suas agendas administrativas tais questões, e em janeiro de 2014, com a queda no volume de chuvas e a redução constante nos reservatórios da região Sudeste, medidas efetivas e emergenciais tiveram que ser adotadas (GALVÃO; BERMANN, 2015, p. 58).

Na especificidade do Sistema Cantareira, RS afirma que todo o sistema tem uma capacidade potencial de 100 110 $\mathrm{m}^{3} / \mathrm{seg}$., pela extensão da bacia, sendo mais de $2 / 3$ para saneamento. A Sabesp tem outorgada em torno de $60 \mathrm{~m} 3 / \mathrm{s}$, que denota uma superexploração e um uso conflituoso entre duas conurbações urbanas de Campinas e São Paulo. "E agora a ANA tem atuação destacada de decisão de políticas públicas na crise hídrica, reduzindo a dominância econômica da Sabesp, que sempre se comportou como uma espécie de Petrobrás da água, com seus interesses econômicos (RS)”:

Pois caberia, no caso dos conflitos ambientais, identificar o tipo específico de "capital" em jogo e o modo como as estratégias discursivas modificam o poder relativo sobre o mesmo. Ou seja, verificar o modo como as remissões ao meio ambiente ou contestam a distribuição de poder sobre o território e seus recursos. É à luz desta pergunta que poderemos, por exemplo, entender como empresas do setor elétrico podem alegar fazer estudos ambientais requeridos por lei ou pela precaução ecológica, mantendo, todavia, intocável o escopo convencional de seus projetos de apropriação do meio para fins energéticos (ACSELRAD, 2004, p. 20).

O uso múltiplo das águas em reservatórios é tema ainda a ser normatizado. A falta de mecanismos institucionais que disciplinem de forma adequada o conflito entre a geração de energia e demais usos; por configurar em impasses de difícil superação (GALVÃO; BERMANN, 20015).

Desde a formação do reservatório de Barra Bonita a disputa de interesses entre os atores na área impactada pela construção da usina tem evidenciado os possíveis conflitos ocorridos ao longo do seu processo histórico, como pode ser destacado no Quadro 2. 
Ações compartilhadas para uso e conservação dos reservatórios Billings e Barra Bonita

Daniel Ladeira Almeida

Quadro 2 - Histórico dos possíveis conflitos ocorridos no reservatório de Barra Bonita

\begin{tabular}{|c|c|c|}
\hline Atores & Impactos socioambientais & Conflitos \\
\hline $\begin{array}{c}\text { Oleiros e } \\
\text { construtores da } \\
\text { usina }\end{array}$ & $\begin{array}{c}\text { Comprometimento da produção } \\
\text { ceramista e inundação de várzeas }\end{array}$ & $\begin{array}{c}\text { Atividade ceramista e geração } \\
\text { de energia }\end{array}$ \\
\hline $\begin{array}{c}\text { Geração de } \\
\text { energia e hidrovia }\end{array}$ & $\begin{array}{c}\text { Desequilíbrio no aporte hídrico em } \\
\text { situações de escassez hídrica }\end{array}$ & $\begin{array}{c}\text { Manter a vazão do reservatório } \\
\text { e garantir a navegabilidade }\end{array}$ \\
\hline $\begin{array}{c}\text { Sociedade civil e } \\
\text { poder público }\end{array}$ & $\begin{array}{c}\text { Ocupações irregulares, desmatamento } \\
\text { e assoreamento }\end{array}$ & $\begin{array}{c}\text { Uso e ocupação do solo e } \\
\text { responsabilidade na destinação } \\
\text { de efluentes não tratados }\end{array}$ \\
\hline
\end{tabular}

Fonte: elaborado pelo autor

A concessionária AES-Tietê da usina hidrelétricas de Barra Bonita são atores importantes nesse contexto:

A ideia da introdução de regras nas outorgas e nos contratos de concessão definidos entre a União e as companhias de geração de energia elétrica, no sentido de incorporarem os usos múltiplos das águas nas condições de operação dos reservatórios das usinas hidrelétricas, comparece como passo necessário de definição (GALVÃO; BERMANN, 2015, p. 66).

Nessa perspectiva, o reservatório de Barra Bonita, construído com o objetivo de suprir a demanda por energia elétrica, promoveu intensas transformações na economia regional, favorecendo os múltiplos usos das águas disponíveis na bacia hidrográfica do Rio Tietê. Esse estímulo econômico contribuiu para o crescimento urbano, que por sua vez, dificilmente possui os recursos provenientes da geração de energia para atender a todos os critérios que atendem ao saneamento ambiental.

No âmbito da fiscalização de usos de recursos hídricos visando priorizar a segurança hídrica é fundamental que haja aumento da quantidade de campanhas de fiscalização em campo, com apoio de imagens de satélite; com o cumprimento das regras de restrição de uso da água com os usuários de recursos hídricos; verificação de defluência de reservatórios e articulação com órgãos gestores estaduais e municipais (ANA, 2015).

Estudos que relacionam o crescimento populacional à poluição dos recursos hídricos demonstram que entre 1990 e 2002 houve um aumento significativo da carga de nitrogênio e fósforo. Isso justifica o possível incremento na emissão de efluentes sanitários não tratados nos cursos d'água, uma das principais fontes de poluição pontual que atinge o reservatório de Barra Bonita (PRADO; NOVO, 2007).

As práticas de urbanização exercidas no Brasil a partir da década de 1970 procurou canalizar córregos para receber edificações que permite ocultar o esgoto lançado no curso d'água: 
A ocupação das áreas dos rios, portanto, não foi fruto apenas de uma ocupação desordenada, como se deixa entender, mas de uma ação deliberada de agenciamento das técnicas disponíveis para a restrição das áreas dos rios visando disponibilizar áreas para urbanização (ANELLI, 2015, p. 71).

Segundo os estudos de Prado e Novo (2007), também houve alterações quanto ao uso e ocupação do solo em áreas de mananciais de 1990 a 2002. Os resultados indicaram a ocorrência de um processo gradativo de expansão das fronteiras agrícolas e urbanas, comprometendo os remanescentes de vegetação natural e gerando uma carga maior de poluentes pontuais e difusos:

Ao se considerar o potencial poluidor da bacia de contribuição para o reservatório de Barra Bonita de 1990 para 2002, em relação ao uso do solo, percebe-se que mudanças estão ocorrendo, porém, ainda pouco perceptíveis em termos de área para a escala de estudo adotada para o mapeamento (PRADO; NOVO, 2007, p. 16).

Entretanto, tais resultados direcionam para o agravamento no processo de assoreamento e eutrofização do reservatório de Barra Bonita, caso as instituições que zelam, operam e utilizam o reservatório não adotem ações integradas de preservação dos mananciais.

A evolução da expansão urbana no estado paulista irradiou de áreas já densamente povoadas dos centros urbanos adentrando para os mananciais dos reservatórios. Essa expansão ocorreu principalmente pela formação de loteamentos irregulares que aqueceu a comercialização de terrenos de baixo valor imobiliário comprados pela população de baixa renda, seguido pelo surgimento de atividades produtivas informais destituídas de quaisquer infraestruturas de saneamento ambiental.

A oposição entre natureza e sociedade é uma construção do século XIX, que serve ao duplo propósito de controlar e ignorar a natureza. A natureza foi subjugada e explorada no final do século XX e, assim, transformada de fenômeno externo em interno, de fenômeno predeterminado em fabricado. Ao longo de sua transformação tecnológico-industrial e de sua comercialização global, a natureza foi absorvida pelo sistema industrial. Dessa forma, ela se converteu, ao mesmo tempo, em pré-requisito indispensável do modo de vida no sistema industrial (BECK, 2011).

Esses fatores estão inseridos em um processo histórico baseado na ampliação dos meios produtivos para manter a escalada do desenvolvimento econômico, sustentado na concepção retórica de recursos hídricos inesgotáveis. Dessa forma, perpetuaram passivos ambientais, como desmatamento em áreas de mananciais, assoreamento e lançamento de 
efluentes não tratados nos reservatórios; práticas as acumulam a um alto custo ambiental e econômico para serem revertidas pelos mantenedores do reservatório:

Surge, dessa maneira, uma genuína contradição, que sistematicamente se aprofunda, entre os interesses de lucro e propriedade que impulsionam o processo de industrialização e suas diversas consequências ameaçadoras, que comprometem a desapropriam inclusive os lucros e a propriedade (para não falar da propriedade da própria vida) (BECK, 2011, p. 46).

É evidente que a poluição hídrica, desmatamento e ocupação de mananciais, falta de planejamento na construção de novos reservatórios, falta de investimentos para redução de perdas de água e falta de cooperação entre instituições, são resultados de ações fragmentadas de gestores dos recursos hídricos preocupados em atender as demandas de curto prazo de forma a controlar investimentos para pilhar recursos financeiros. Com isso, as instituições direcionam seus investimentos em ações que visam ampliar os lucros, trazendo benefícios de curto prazo.

Ao comparar os lucros obtidos no setor energético em relação ao abastecimento público, foi questionado para os(as) responsáveis da Emae sobre como a empresa discerne a respeito do bombeamento das águas poluídas do rio Pinheiros para garantir a geração de energia ou reverter recursos para despoluição de rio e represa favorecendo, ao abastecimento público.

É correto afirmar que a pressão sobre os recursos hídricos é resultado da alta demanda pelo abastecimento público, e o setor hidrenergético age passivamente quanto a demanda pelos recursos hídricos? Justifique.

Sobre essa questão RE1, acredita que no Brasil há uma carência de planejamento estratégico em quase todos os campos, essencialmente quanto aos setores de desenvolvimento econômico e social. Afirma que um país com as dimensões do Brasil com água em abundância numa região e faltando em outra não pode concentrar a maior parte de suas atividades produtivas numa determinada região. E RE1 defende que o setor elétrico é um dos únicos segmentos produtivos que se preocupou em exercer um planejamento em médio e longo prazo, pois o resultado do seu planejamento demanda muitos anos para tomar forma. Com relação ao reservatório Billings, o(a) entrevistado(a) diz que é inegável o crescimento da região do Grande $\mathrm{ABC}$ fez com que ampliasse a demanda em entorno aproveitando água e energia elétrica. Com isso seria interessante uma postura mais estratégica por parte das instâncias governamentais e estabelecer um limite para o crescimento das cidades e a clareza 
que um dado momento não vai ter água para todas as pessoas, sem contar que será preciso recuperar a produção nos represamentos existentes para manter a geração de energia elétrica.

No caso da região metropolitana de São Paulo, dos 39 municípios da região, 23 apresentaram índices de atendimento de água acima de 98\%; sete entre 91\% e 97\%; e nove entre $58 \%$ e $90 \%$. Com relação ao atendimento de coleta de esgotos, apenas quatro municípios apresentaram índices acima de 90\%; 16 entre 60\% e 89\%; dez entre 30\% e 59\%; e nove entre $0 \%$ e $29 \%$, sendo que, destes, Juquitiba e São Lourenço da Serra não apresentaram atendimento em coleta de esgotos (FRACALANZA; CAMPOS, 2006). Entre as metas da Sabesp para 2016, é de que todo esgoto coletado na Região Metropolitana de São Paulo seja 86\% devidamente tratado em suas estações de tratamento de esgoto (SABESP, 2016b).

Mesmo protegidas legalmente como APP, encostas, margens de recursos hídricos e várzeas estão densamente ocupadas por favelas e construções inadequadas iniciadas durante o processo de crescimento da população urbana na segunda metade do século XX, em razão da ineficiência das políticas habitacionais que atendesse à população. Por isso é necessária a recuperação dessas áreas para que ocorra a despoluição das águas, o que exige ações integradas entre usuários das águas e setores não pertencentes ao setor de saneamento (ANELLI, 2015).

Considero que a pressão está ligada à crônica escassez (quantidade) dos recursos hídricos (estamos situados próximos às cabeceiras do Rio Tietê) e também devido à má qualidade da água devido ao baixo tratamento de volumes de esgoto realizado pela Companhia de Saneamento que opera na região. A alta demanda para abastecimento público se soma ao contexto apresentado e é agravado pelas perdas no sistema de distribuição de água e também pela cultura do desperdício e uso perdulário que prevalece em nossa sociedade. É inegável o uso prioritário do recurso hídrico para abastecimento público. No entanto, a maneira como ele é feito, prejudica a disponibilidade para outros usos hídricos importantes, inclusive a geração de energia. E por fim, de fato, apesar do setor hidrenergético (EMAE) no Alto Tietê ser o proprietário de importantes reservatórios (Billings e Guarapiranga), ele está à mercê dos interesses elencados pelo Governo do Estado de São Paulo que é sócio majoritário da empresa (RE2).

De acordo com artigo 15 da Lei ${ }^{\circ} 13.579$ (SÃO PAULO, 2009), fica estabelecido como meta de qualidade da água do reservatório Billings a ser atingida até o ano de 2015 a redução da carga de fósforo nos respectivos braços do reservatório, como descrito no Quadro 3.

Quadro 3 - Perspectiva de redução da carga de fósforo no reservatório Billings

\begin{tabular}{|c|c|} 
Braços do reservatório Billings & $\begin{array}{c}\text { Quantidade a ser reduzida } \\
\text { de fósforo }\end{array}$
\end{tabular}




\begin{tabular}{|c|c|}
\hline Corpo Central I & $135 \mathrm{~kg} / \mathrm{dia}$ \\
\hline Corpo Central II & $11 \mathrm{~kg} / \mathrm{dia}$ \\
\hline Taquacetuba Bororé & $27 \mathrm{~kg} / \mathrm{dia}$ \\
\hline Capivari Pedra Branca & $5 \mathrm{~kg} / \mathrm{dia}$ \\
\hline Rio Grande Rio Pequeno & $103 \mathrm{~kg} / \mathrm{dia}$ \\
\hline
\end{tabular}

Fonte: baseado na Lei ${ }^{\circ} 13.579$ (SÃO PAULO, 2009).

Conforme o artigo 54 da Lei n¹3.579 (SÃO PAULO, 2009), são responsáveis pelo monitoramento da qualidade ambiental do reservatório Billings, no limite de suas competências e atribuições, os órgãos e entidades da administração pública estadual e municipal com atuação na área de meio ambiente, recursos hídricos, saúde, agricultura, saneamento, energia, entre outros; assim como, concessionárias de serviços públicos de abastecimento de água, coleta e tratamento de esgotos sanitários, gestão de resíduos sólidos, entre outras.

Segundo estudos realizados pela Expedição Mananciais 2016 - Reservatório Billings e Guarapiranga, o laudo técnico previsto no projeto de Índice de Poluentes Hídricos aponta $0,06 \mathrm{mg} / \mathrm{L}$ de fósforo presente em amostras das águas do braço do Corpo Central II do reservatório, nos 18 pontos coletados na cidade de São Bernardo do Campo - SP. Isso representa o dobro de fósforo do que é permitido pela Resolução Conama 357/2005 (0,03 $\mathrm{mg} / \mathrm{L}$ ) e inferior as perspectivas de redução de fósforo previstas na Lei Específica da Billings, resultado do lançamento contínuo de efluentes não tratados, o que eleva a concentração de nutrientes - especialmente nitrogênio e fósforo - que propiciam a eutrofização desses corpos d'água, permitindo a proliferação excessiva de algas, fenômeno conhecido como "blooms" (MARCONDES, 2016).

O bombeamento proveniente do Rio Pinheiros para o Reservatório Billings em 2015 correspondia a uma vazão média anual de $8,6 \mathrm{~m}^{3} / \mathrm{s}$, superior à média do ano anterior $(5,1$ $\mathrm{m}^{3} / \mathrm{s}$ ). Isso refletiu para o decaimento da qualidade da água na represa, implicando numa maior concentração de fósforo $(0,35 \mathrm{mg} / \mathrm{L})$, devido ao aumento da ocorrência do processo de diluição do fósforo ao longo do corpo central e no trecho final, na saída das águas desse reservatório (CETESB, 2016).

Dessa forma, as metas de despoluição do reservatório Billings ainda estão por atingir a sua totalidade, como previsto na Lei Específica da Billings. Por isso, é necessário que operadores, usuários e poder público desenvolvam ações compartilhadas de preservação dos mananciais do reservatório para evolução da despoluição das águas do reservatório Billings.

\section{Considerações Finais}


A conscientização para preservação dos recursos ambientais ocorre quando há o entendimento do Estado com a iniciativa privada partindo de uma forte demanda da sociedade civil organizada. E a degradação ambiental é o resultado de uma grande desordem na exploração e gestão dos bens comuns da humanidade por parte das grandes empresas e dos atores políticos orientados por uma ideia individualista e mecaniscista.

Nesse artigo identificamos que as leis ambientais não foram suficientes para garantir um engajamento efetivo para conter os passivos ambientais que atingem os reservatórios, e que o apreveitamento econômico proveniente dos recursos hídricos ainda são pouco convertidos para garantir a sua preservação para as futuras gerações.

É evidente que a economia é um importante elemento de transformação das sociedades, e não se trata de exterminá-lo, mas reverter parte dos seus crescimentos para garantir a conservação dos resursos ambientais. Desenvolver ações compartilhadas para preservação de um reservatório exige compartilhar os custos ambientais, e o Estado, cada vez mais inserido em um mercado mundializado a serviço das grandes empresas, está cada vez mais distante das preocupações ambientais que possa levar um crescimento econômico sustentável.

As ações conflitantes pelo uso da água entre os usuários e operadores dos reservatórios podem configurar em um cenário de elaboração de medidas que reduzam os passivos ambientais que atingem os reservatórios. Tais medidas consistem em garantir o uso compartilhado do reservatório com o mínimo de conflitos entre o uso energético e o abastecimento público.

Para que haja uma gestão de recursos hídricos de forma integrada, exige-se uma coalizão de forças de diversos atores que utilizam a água como recurso principal na atividade produtiva. Dessa forma, a avaliação da gestão pública é baseada nos investimentos (gastos de recursos) em determinados setores e dificilmente os resultados são devidamente analisados. E são os resultados que podem constituir proposta de qualificação da gestão.

Por isso, ações compartilhadas para a gestão de um reservatório exige cooperação e políticas públicas articuladas, algo que não são soluções fáceis de se atingir, porque a responsabilidade de se atingir isso não restringe apenas ações pontuais do Estado ou das grandes empresas, mas a partir da construção de consensos na sociedade que cobra do Poder Público, por meio de processo coletivos de pressão, que o mercado assuma os custos gerados pelos passivos ambientais, e sobretudo que exige que o Estado implemente políticas públicas articuladas de reservação dos reservatórios.

\section{Referências}


ABRANCHES, S. H. A questão da empresa estatal: economia política e interesse público. Revista de Administração de Empresa, Rio de Janeiro, v. 4, n. 19, p. 95-105, out./dez, 1979. Disponível em: <https://rae.fgv.br/rae/vol19-num4-1979/questao-empresa-estataleconomia-politica-interesse-publico>. Acesso em: 12 jun. 2020.

ACSELRAD, H. As práticas espaciais e o campo dos conflitos ambientais, In: ACSELRAD, Henri. (org.) Conflitos ambientais no Brasil. Rio de Janeiro: Relume Dumará, 2004, p. 1335 .

AES-BRASIL. Perfil das Usinas AES Tietê. Disponível em: <http://www.aesbrasil.com.br/indicadores/2006/port/rs_tiete/01.htm>. Acesso em: 14 mai. 2014.

ANA. Agencia Nacional de Águas. Conjuntura dos recursos hídricos no Brasil - Encarte $\begin{array}{llllll}\text { Especial sobre } & \text { a } & \text { Crise } & \text { Hídrica. } & \text { Disponível } & \text { em }\end{array}$ <http://conjuntura.ana.gov.br/docs/crisehidrica.pdf>. Acesso em: 9 jul. 2016.

ANEEL. Guia de avaliação de assoreamento de reservatórios. Disponível em: <http://www2.aneel.gov.br/biblioteca/downloads/livros/Guia_ava_port.pdf.> Acesso em 12 jun. 2020.

ANELLI, R. L. S. Uma nova cidade para as águas urbanas. São Paulo: Estudos Avançados, v. 29, n. 84, p. 69-84, maio-agosto, 2015. Disponível em: < https://www.scielo.br/pdf/ea/v29n84/0103-4014-ea-29-84-00069.pdf>. Acesso em: 12 jun. 2020.

AQUINO, L.C.S. Recuperação florestal de margens de reservatórios: proteção dos recursos hídricos, manutenção da biodiversidade e recomposição da paisagem. In: CAMPOGNOLI, F.; DINIZ. N. C (orgs). Gestão de reservatório de hidrelétricas. São Paulo: Oficina de Textos, 2012, p. 131-143.

AUtOMARE, M. M. Água: a escolha da ciência. São Paulo: Estudos Avançados, v. 29, n. 84, p. 103-114, maio-agosto, 2015.

BECK, U. Sociedade de risco: rumo a uma outra modernidade. $2^{\text {a }}$ ed. São Paulo: Editora 34, 2011.

BRASIL. Ministério do Meio Ambiente. Plano Nacional de Recursos Hídricos. Brasília, DF: MMA, 2006.

CAMPAGNOLI, F.; TUNDISI, J.G. Desafios na gestão de reservatórios de hidrelétricas no Brasil. In: CAMPOGNOLI, F.; DINIZ. N. C (orgs). Gestão de reservatório de hidrelétricas. São Paulo: Oficina de Textos, 2012, p. 175-182.

CAMPAGNOLI, F. Gestão de reservatórios de hidrelétricas: o potencial hidráulico da união gerido como recurso renovável. In: CAMPOGNOLI, F.; DINIZ. N. C (orgs). Gestão de reservatório de hidrelétricas. São Paulo: Oficina de Textos, 2012a, p. 11-14. 
CARMO, R. L. do. A água é o limite? Redistribuição espacial da população e recursos hídricos no Estado de São Paulo. Tese de doutorado apresentado ao Instituto de Filosofia e Ciências Humanas, Universidade Estadual de Campinas, Campinas, 2001. 203 p.

CETESB. Institucional. Histórico. Disponível em: <http://www.cetesb.sp.gov.br/institucional/histórico/>. Acesso em: 15 mar. 2016.

CÔRTES, P.L.; TORRENTE, M. Crise de abastecimento de água em São Paulo e falta de planejamento estratégico. Estudos avançados, São Paulo: IEA, v. 29, n. 84, p. 7-26, maio/agosto, 2015.

FRACALANZA, A.P.; CAMPOS, V.N. O. Produção social do espaço urbano e conflitos pela água na região metropolitana de São Paulo. São Paulo em Perspectiva, São Paulo, Fundação Seade, v. 20, n. 2, p. 32-45, abr./jun. 2006. Disponível em: $<$ http://produtos.seade.gov.br/produtos/spp/v20n02/v20n02_03.pdf $>$. Acesso em: 12 jun. 2020.

GALVÃO, J.; BERMANN, C. Crise hídrica e energia: conflito no uso múltiplo das águas. São Paulo: Estudos Avançados, v. 29, n. 84, p. 43-68, mai-ago, 2015.

GOMES, J.L.; BARBIERI, J.C. Gerenciamento de recursos hídricos no Brasil e no estado de São Paulo: um novo modelo de política pública. São Paulo: Cadernos Ebape.BR, v. 2, n. 3, p. 1-21, dezembro, 2004.

GRANZIERA, M. L. M. Direito de Águas. Jornal Carta Forense, São Paulo, 03/05/2014. Disponível em: <http://www.cartaforense.com.br/conteudo/entrevistas/direito-deaguas/14507>. Acesso em: 09 ago. 2016.

INSTITUTO TRATA BRASIL. Ociosidade das Redes de Esgoto. Disponível em: <http://www.tratabrasil.org.br/datafiles/estudos/ociosidade/relatorio-completo.pdf>. Acesso em: 08 out. 2016.

ITAIPU. Relatório de Sustentabilidade 2014. Curitiba: Itaipu Binacional, 2015. 124p.

JACOBI, P.R.; CIBIM, J.; LEÃO, R.S. Crise hídrica na macrometrópole paulista e respostas da sociedade civil. Estudos avançados, São Paulo: IEA, v. 29, n. 84, p. 27-42, maio/agosto, 2015a.

JACOBI, P.R. et al. Governança da água no Brasil. In: JACOBI, P.R.; FRACALANZA, A.P.; EMPINOTTI, V. Governança da água no contexto ibero-americano: inovação em processo. São Paulo: GovAmb: Procam USP: Annablume, 2015b, p. 11-28.

MARCONDES, M. A. Expedição mananciais 2016: reservatório Billings Guarapiranga. Projeto IPH - Índice de Poluentes Hídricos. Disponível em: <www.uscs.edu.br/boletim/?idf=3267>. Acesso em: 22 jul. 2016.

PRADO, R.B.; NOVO, E.M.L. Avaliação espaço-temporal da relação entre o estado trófico do reservatório de Barra Bonita (SP) e o potencial poluidor de sua bacia hidrográfica. Sociedade e Natureza, Uberlândia, v. 2, n. 19, p. 5-18, dezembro 2007. 
RAMALHO, M.L. Território e macrossistema elétrico nacional: as relações entre privatização, planejamento e corporativismo. Dissertação de mestrado em Geografia apresentado ao Programa de Pós-graduação em Geografia Humana, Universidade de São Paulo, São Paulo, 2006. $201 \mathrm{f}$

SABESP. Índices de coleta e tratamento. Disponível em: <http://site.sabesp.com.br/site/interna/Default.aspx?secaoId=631>. Acesso em: 15 out. 2016.

SEADE. Sistema Seade de Projeções Populacionais. São Paulo: SEADE, 2016, Disponível: <http://produtos.seade.gov.br/produtos/projpop/>. Acesso em: 9 jul. 2016.

SÃO PAULO (Estado). Lei $n^{\circ} 13.579$, de 13 de julho de 2009. Define a área de proteção e recuperação dos mananciais Billings - APRA-B, e dá outras providências correlatas. Diário Oficial. São Paulo, 16 setembro 2009. Disponível em: <www.legislacao.sp.gov.br>. Acesso em: 18 jul. 2016.

TEIXEIRA, C.G. Pagamento por serviços ambientais de proteção às nascentes como forma de sustentabilidade e preservação ambiental. Dissertação de mestrado em Direito apresentado ao Programa de Pós-Graduação em Direito Socioambiental, da Pontifícia Universidade Católica do Paraná, Curitiba, 2011. 198 f

VARGAS, M. C. O negócio da água - riscos e oportunidades das concessões de saneamento à iniciativa privada: estudos de caso no Sudeste brasileiro. São Paulo: Annablume, 2005. 